\title{
Effectiveness of 3 P Implementation (People, Process, Physical Evidence) And Company Performance At Different Levels Of Complexity And Divergence
}

\author{
Anggoro Destu Adhi
}

Program Studi Manajemen, Fakultas Ekonomi, Universitas Sanata Dharma Yogyakarta, Indonesia

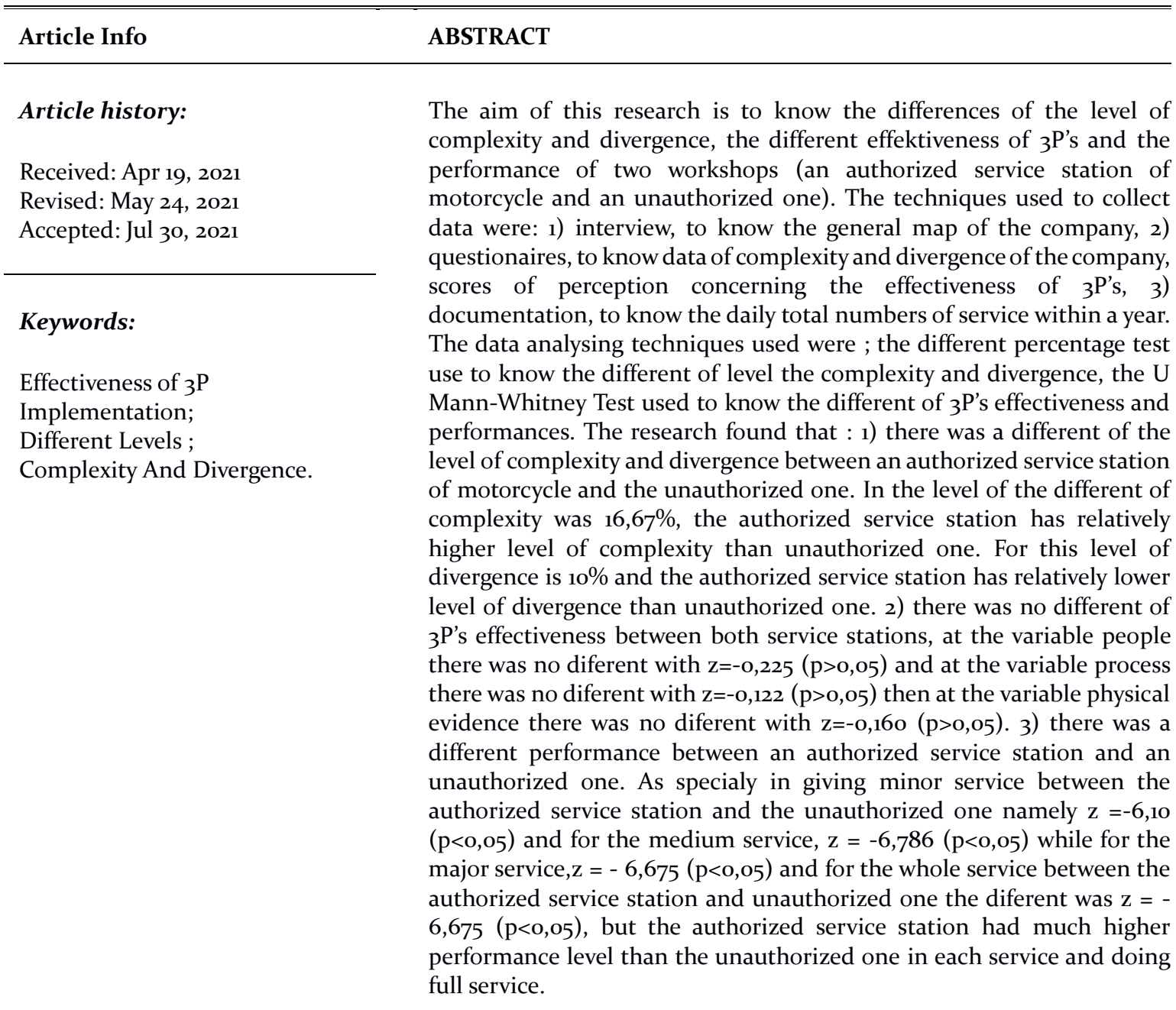

This is an open access article under the CC BY-NC license.

Corresponding Author:

Anggoro Destu Adhi

Program Studi Manajemen, Fakultas Ekonomi,

Universitas Sanata Dharma Yogyakarta, Indonesia,

Jl. Affandi, Santren, Caturtunggal, Kec. Depok, Kabupaten Sleman, Daerah Istimewa Yogyakarta 55281

Email: anggorodestu@gmail.com 


\section{INTRODUCTION}

In our daily life, we often encounter various kinds of service businesses. Among them are the business of telecommunications services (telephone and facsimile), insurance, television entertainment, education, laundry, hotels, restaurants, repairs, workshops and financial services. These various types of services are a small part of the many types of services that are developing today (Papazoglou \& Van Den Heuvel, 2006). It can be said that how influential the service business is in the modern world(Oke et al., 2009). Currently, every consumer is no longer just buying a product, but also aspects of services or services attached to the product, starting from the pre-purchase stage to the post-purchase stage (Lindberg \& Nordin, 2008) (Long, 2010). When viewed from the company's point of view, one of the effective ways to differentiate is through the services provided. This brings a fairly basic change in the main business of a company (Halinen \& Törnroos, 2005). For example, the main business of a restaurant shifts from just providing all kinds of food for sale, to an effort to serve and satisfy the hunger of customers accompanied by efforts to provide a conducive atmosphere for customers to enjoy a meal(Erickson, 2009)(Kimmel, 2010)(Shanmoogam, 2006). Another example is a computer company, where what they sell is a solution, not just a physical product(Teece, 2010). This is because consumers buy computers mainly used to work on or solve problems, so the role of computers is more as a tool(Armbrust et al., 2009). Thus, all aspects of services or services such as installation, repair, consultation on how to use, and others become an inseparable part of the computers sold(Cusumano et al., 2008). Various kinds of service facilities or services offered by the company are also related to various customer needs. Fulfillment of customer needs and customer satisfaction is one of the company's goals. Good company performance is also the company's goal(Ismail et al., 2006)(Longo et al., 2005). To achieve these goals required a tool called the marketing mix. The formulation and implementation of an effective marketing mix is what companies want in the formulation and implementation of marketing strategies(Goi, 2009)(Ho \& Hung, 2008)(Dominici, 2009). The concept of the traditional marketing mix which was formulated with the ${ }_{4} \mathrm{Ps}$ (Product, Price, Promotion, and Place) in its development, for the service business, is considered too limited or narrow due to the weaknesses contained in the service business(Akraush, 2005). These weaknesses encourage many marketing experts to add or expand with four other elements, namely People, Process, Physical evidence, and Customer service. Decisions regarding each element of the marketing mix are interrelated(Zineldin \& Philipson, 2007)(Ahmad, 2007). However, the level of importance assigned to each element between services tends to vary. In addition to Product, Place, Promotion, and Price, other important components in the service marketing mix that are no less important are People, Process, and Physical evidence. These three elements often reflect the services offered and play a significant role in making the "realization of the intangible". The characteristics of service intangibility have implications for the difficulty of customers evaluating a service before the service is consumed and in turn will cause the perception of purchase risk to increase significantly(Keh \& Pang, 2010)(Laroche et al., 2005)(Laroche et al., 2010). Therefore, an important element in marketing planning is to reduce the level of risk by offering physical evidence for the delivery of the promised service. This physical evidence can vary, including brochures, employee appearances, buildings and physical facilities, guarantees and so on. For most services, human resources (people) are a vital element of the marketing mix. Human resource management has a significant impact on the company's service offering in four main aspects(Mudie \& Cottam, 2010). First, Most service production processes require service organization staff to provide significant input on the service production process, both on the front-line and back-line processes. Second, many service processes require the active involvement of service consumers. Consequently, consumers become co-producers of services(Stiglingh, 2009). Third, other people who at the same time consume a mass-produced service can affect the benefits that certain individuals receive from the service concerned. Fourth, every company can create a competitive advantage through the creation and delivery of personal differentiation. Meanwhile, the process includes actual procedures, tasks, and stages of activities carried out in order to produce and deliver services or services. The service process is supported by two very important elements, namely people and physical evidence(Bitner et al., 2008). Broadly speaking, service processes can be grouped based on two main characteristics, namely complexity and divergence. 
Complexity concerns the number and intricacies (intricacies) of the steps required to perform a service or services(Kirkpatrick et al., 2005). While divergence is the level of variability, freedom, judgment, flexibility or situational adaptation that is allowed in a process step. Through the classification of complexity and divergence, service companies can be grouped into two(Seidel et al., 2010)(Ba \& Johansson, 2008). This grouping can still be subdivided based on the high-low level of complexity and divergence that the company has. Based on these groupings, companies can be grouped into four groups, namely groups with high complexity-high divergence, high complexity-low divergence, low complexityhigh divergence, and low complexity-low divergence. Service customers generally prefer and expect a service delivery process with a low level of complexity, in other words they prefer and expect a simple service delivery process(Bowen \& Lawler III, 2006)(Simon \& Usunier, 2007). With the many needs of existing customers will have an impact on the many kinds of needs that are different from each other, service businesses are required to be able to meet their needs. Service providers who are able to meet customer needs can survive in business competition. This is because consumers prefer service providers who can truly meet their needs. Customer needs relate to the level of variability, freedom, judgment, flexibility or situational adaptation that is allowed(Kashdan \& Rottenberg, 2010). Therefore, consumers will prefer service providers that provide a high level of divergence because here the services are customized according to the preferences of each customer. Customer perception will have a significant impact on the level of purchase(Siddiqui \& Sharma, 2010)(Malai \& Speece, 2005). A good perception will increase purchases and repurchase which will improve the performance of service providers. Starting from the understanding that has been described above, the author tries to research and analyze the effect given on the effectiveness of the implementation of the ${ }_{3}$ Ps (People, Process, and Physical evidence) on the company's performance, at different levels of complexity and divergence(Hume et al., 2006)(Prahinski \& Kocabasoglu, 2006). The vehicle repair shop, especially for two-wheeled vehicles, is one of the many service companies that prioritize customer satisfaction. When customers are satisfied, their tendency to repurchase the services offered is getting bigger(Weber, 2009)(Belzowski et al., 2007). It is the consumer who deserves to be the judge of all the services and facilities offered by a workshop. In the city of Yogyakarta, there are many motorcycle repair shops that are managed by the community itself which are often understood by the public as regular or non-official repair shops and some are under the supervision of a motorcycle company which is often understood by the public as official workshops(Janssen, 2005).

\section{RESEARCH METHOD}

The type of research carried out is field research or case studies, research on certain objects where researchers take research in several companies by looking for data and existing problems for further research. The data is processed and analyzed to produce conclusions(Runeson \& Höst, 2009)(Ahrens \& Chapman, 2006). The population in this study are all customers or people who have used and used the services in the workshop, from the two workshops that became the research location. The sample of this research is service users from both workshops. The sampling technique used was the stratifiedaccidental sampling method, namely sampling by grouping the population with certain criteria into several strata and found by chance. This study will take the number of samples using the following formula (Kadam \& Bhalerao, 2010).

Where:

$$
n=\left[\frac{Z}{E}\right]^{2} \times 0,5
$$

$\mathrm{n} \quad=$ sample size

$\mathrm{Z} \quad=\mathrm{z}$ value whose magnitude is determined by the confidence interval

$\mathrm{E} \quad=$ magnitude of the expected error

With $95 \%$ confidence interval, then $\mathrm{Z}$ is 1.96 . The error rate is $10 \%$. So the number of samples needed is 96.04, to simplify the calculations the researchers rounded off the number of samples by 100 in each workshop. 


\subsection{Data collection technique}

Interviews were conducted with parties from companies that have information needed by researchers regarding company performance(Skibniewski \& Ghosh, 2009). The party in question is the leader or owner of the workshop. The researcher also provides several questions that will describe the level of complexity and level of divergence of the company. The questionnaire is addressed to respondents, the intended respondents are customers who use the services of a workshop. Documentation is done by collecting data by copying data or company information related to the problem under study. The data in question are service implementation reports(Moody et al., 2004).

\subsection{Data analysis technique}

To distinguish the level of complexity and divergence obtained from the scores of several statements submitted to the workshop owner. To find out the magnitude of the difference, the researcher will percentage the difference by percentage of the difference in scores from the two workshops.

$\begin{array}{ll}\text { Maximum score } & =2 \times \mathrm{N} \\ \text { Minimum score } & =1 \times \mathrm{N} \\ \mathrm{N} & =\text { number of statements } \\ \text { Biggest difference } & =\text { max score }- \text { minimum score } \\ \text { Biggest difference percentage } & =100 \% \\ \text { Percentage difference } & =(\text { difference in score } \times 100 \%): \mathrm{N}\end{array}$

To test the second hypothesis used calculations based on the analysis of U Mann-Whitney Test(Nachar, 2008). This analysis is used to determine whether there is a difference in the effectiveness of ${ }_{3} \mathrm{P}$ between official workshops and ordinary workshops, when viewed from the level of complexity and divergence.

\section{RESULTS AND DISCUSSIONS}

In this section the author will analyze the data that has been done quantitatively. Data analysis in this study consists of three parts. In the first part, instrument testing will be carried out consisting of validity and reliability tests on questionnaires distributed to research locations. A total of 100 questionnaires were distributed and filled in at the research location at the Yamaha Arditya Buana Motor motorcycle repair shop. Questionnaires were distributed and filled in from November 2008 to October 2009, with the division of time and the number of questionnaires distributed, 8 questionnaires per month. At the same time, as many as 100 questionnaires were distributed and filled out at the research location at the Imung Baru Motor motorcycle repair shop. Questionnaires were distributed and filled in from November 2008 to October 2009, with the division of time and the number of questionnaires distributed, 8 questionnaires per month. The second part consists of three parts. The first is the percentage difference test, this calculation is used to determine the percentage difference in the level of complexity and divergence in official workshops with ordinary workshops. Second, analysis of the Mann-Whitney U Test. This analysis is used to determine whether there is a difference in the effectiveness of ${ }_{3} \mathrm{P}$ in official workshops with ordinary workshops. And thirdly, U Mann-Whitney test analysis, this analysis is used to determine the difference in the performance of the workshop at the rummy workshop with the regular workshop. The third part is a discussion of the data analysis that has been carried out. The discussion contains a description of the results of data analysis and answers to the problems studied. The first is the percentage difference test, this calculation is used to determine the percentage difference in the level of complexity and divergence in official workshops with ordinary workshops. Second, analysis of the Mann-Whitney U Test. This analysis is used to determine whether there is a difference in the effectiveness of ${ }_{3} \mathrm{P}$ in official workshops with ordinary workshops. And thirdly, U Mann - Whitney test analysis, this analysis is used to determine the difference in the performance of the workshop at the rummy workshop with the regular workshop. The third part is a discussion of the data analysis that has been carried out. The discussion contains a description of the results of data analysis and answers to the problems studied. The first is the percentage difference test, this calculation is used to determine the percentage difference in the level of complexity and divergence in official workshops with ordinary workshops. Second, analysis of the Mann-Whitney U Test. This analysis is used 
to determine whether there is a difference in the effectiveness of ${ }_{3} \mathrm{P}$ in official workshops with ordinary workshops. And thirdly, U Mann-Whitney test analysis, this analysis is used to determine the difference in the performance of the workshop at the rummy workshop with the regular workshop. The third part is a discussion of the data analysis that has been carried out. The discussion contains a description of the results of data analysis and answers to the problems studied. Mann-Whitney U Test analysis. This analysis is used to determine whether there is a difference in the effectiveness of ${ }_{3} \mathrm{P}$ in official workshops with ordinary workshops. And thirdly, U Mann-Whitney test analysis, this analysis is used to determine the difference in the performance of the workshop at the rummy workshop with the regular workshop. The third part is a discussion of the data analysis that has been carried out. The discussion contains a description of the results of data analysis and answers to the problems studied. Mann-Whitney U Test analysis. This analysis is used to determine whether there is a difference in the effectiveness of ${ }_{3} \mathrm{P}$ in official workshops with ordinary workshops. And thirdly, U Mann - Whitney test analysis, this analysis is used to determine the difference in the performance of the workshop at the rummy workshop with the regular workshop. The third part is a discussion of the data analysis that has been carried out. The discussion contains a description of the results of data analysis and answers to the problems studied.

\subsection{Instrument Testing.}

\section{Validity test.}

Validity test is conducted to measure the validity or validity of a questionnaire. If a questionnaire is said to be valid, it means that the instrument can be used to measure what should be measured. By using the SPSS computer program at a significance level $(\alpha)=0.05$, the validity level of the questionnaire in this study can be calculated as follows:

Table 1. Validity Test on Authorized Workshop Customers

\begin{tabular}{ccccc}
\hline Variable Effectiveness ${ }_{3} \mathrm{P}$ & r count & r table & $\mathrm{r}=0.3$ & Information \\
\hline People 1 & 0.671 & 0.135 & 0.3 & Valid \\
People 2 & 0.710 & 0.135 & 0.3 & Valid \\
People 3 & 0.611 & 0.135 & 0.3 & Valid \\
People 4 & 0.518 & 0.135 & 0.3 & Valid \\
People 5 & 0.636 & 0.135 & 0.3 & Valid \\
Process 1 & 0.666 & 0.135 & 0.3 & Valid \\
Process 2 & 0.630 & 0.135 & 0.3 & Valid \\
Process 3 & 0.714 & 0.135 & 0.3 & Valid \\
Process 4 & 0.518 & 0.135 & 0.3 & Valid \\
Process 5 & 0.336 & 0.135 & 0.3 & Valid \\
Phy Ev 1 & 0.662 & 0.135 & 0.3 & Valid \\
Phy Ev 2 & 0.485 & 0.135 & 0.3 & Valid \\
Phy Ev 3 & 0.569 & 0.135 & 0.3 & Valid \\
Phy Ev 4 & 0.642 & 0.135 & 0.3 & Valid \\
Phy Ev 5 & 0.351 & 0.135 & 0.3 & Valid \\
\hline
\end{tabular}

From the results of the validity tests that have been carried out as presented in the table above, then by comparing the value of $r$ count with $r$ table at the significance level $(\alpha)=0.05$, and comparing $r$ count with $r=0.3$ all question items regarding effectiveness ${ }_{3} \mathrm{P}$ has a value of $\mathrm{r}$ arithmetic $>\mathrm{r}$ table and $\mathrm{r}$ arithmetic $>\mathrm{r}=0.3$. Based on the provisions of the validity test which states that a questionnaire is declared valid if $r$ count $r$ table, then all questions regarding the effectiveness of ${ }_{3} \mathrm{P}$ on official workshop customers are declared valid or none of them fall.

\section{Reliability Test}

Reliability testing in principle shows the extent to which measuring instruments can be trusted and can be relied upon in providing relatively the same results in the same subject in several times of implementation. The item reliability test analysis technique used is Cronbach's Alpha coefficient. By 
using the SPSS computer program at the significance level $(\alpha)=0.05$, the reliability level can be calculated as follows:

Table 2. Reliability Test on Authorized Workshop Customers

\begin{tabular}{cccccc}
\hline Group & r count & r table & $\mathrm{r}=0.6$ & $\mathrm{r}=0.7$ & Information \\
\hline $\begin{array}{c}\text { Authorized repair } \\
\text { shop }\end{array}$ & 0.895 & 0.135 & 0.6 & 0.7 & reliable \\
\hline
\end{tabular}

From the results of the reliability test that has been carried out as presented in the table above, then by comparing the calculated $r$ value with $r$ table at the significance level $(\alpha)=0.05 ; r=0.6$ and $r=0.7$, the ${ }_{3} \mathrm{P}$ effectiveness variable in the official workshop group has a value of $r$ arithmetic $>r$ table; $r$ arithmetic $>\mathrm{r}=0.6$ and $\mathrm{r}$ arithmetic $>\mathrm{r}=0.7$ Based on the provisions of the reliability test which states that a questionnaire is declared reliable if the value of $r$ arithmetic $\geq r$ table, then all ${ }_{3} \mathrm{P}$ effectiveness variables in the official workshop group are declared reliable.

In this study, the questionnaires for both workshops were the same, so the data obtained from the respondents were worthy of analysis.

\subsection{Hypothesis testing}

First Problem Formulation

To answer the formulation of the first problem which states that there are differences in the level of complexity and divergence in the official workshop and the ordinary workshop, a percentage difference test is used which will compare each complexity score and divergence score in the official workshop with the regular workshop. From the comparison of these scores will be known the difference.

Complexity Variable In the official workshop, data on the "YES" option selection with a score of 2 was obtained with a score of 16 and the selection of the "NO" option with a score of 1 with a score of 2. Therefore, in the official workshop the complexity variable had a total score of 34 . While in the ordinary workshop, the selection data was obtained. the "YES" option is 13 and the "NO" option is 5 . That way the normal workshop has a total score of 31. Using the following criteria and formulas:

$\mathrm{N}=$ number of statements

Maximum score $=2 \times \mathrm{N}$ Minimum score $=\mathbf{1} \times \mathrm{N}$

Biggest difference $\quad=$ max score - minimum score

Percentage difference $\quad=($ difference in score $\mathrm{x} 100 \%): \mathrm{N}$

Then obtained:

$$
\mathrm{N}=18
$$

Maximum score $=2 \times 18=36$

Minimum score $=1 \times 18=18$

Percentage of biggest difference $=((36-18) \times 100 \%)): 18$

$$
\begin{aligned}
& =(18 \times 100 \%): 18 \\
& =100 \%
\end{aligned}
$$

Based on the data obtained and using the formula, it is obtained:

Percentage difference $\quad=((34-31) \times 100 \%)): 18$

$$
\begin{aligned}
& =(3 \times 100 \%): 18 \\
& =16.667 \%
\end{aligned}
$$

Based on the calculations above, it can be seen that there are differences in the level of complexity in official workshops with ordinary workshops. Official workshops have a higher level of complexity than ordinary workshops. The difference in the level of complexity is $16.667 \%$. Therefore, the opinion regarding the formulation of the first problem of this study which states that there is a difference in the level of complexity in the official workshop and the ordinary workshop is acceptable.

Divergence Variables In the official workshop, data on the "YES" option was obtained with a score of 2 with a score of 8 and the selection of the "NO" option with a score of 1 with a score of 2. Therefore, in the official workshop, the divergence variable had a total score of 18 . While in the ordinary 
workshop, the selection data was obtained. the "YES" option is 9 and the "NO" option is 1 . That way the normal workshop has a total score of 19. Using the following criteria and formulas:

$\mathrm{N}=$ number of statements

Maximum score $=\mathbf{2} \times \mathrm{N}$

Minimum score

$=1 \times \mathrm{N}$

Biggest difference

$=$ maximum score-minimum score

Biggest difference percentage

$=100 \%$

Percentage difference

$=($ difference in score $\mathrm{x} 100 \%): \mathrm{N}$

Then obtained:

$\mathrm{N}=10$

Maximum score $=2 \times 10=20$

Minimum score $=1 \times 10=10$

Biggest difference percentage

$$
\begin{aligned}
& =((20-10) \times 100 \%)): 10 \\
& =(10 \times 100 \%): 10 \\
& =100 \%
\end{aligned}
$$

Based on the data obtained and using the formula, it is obtained:

Percentage difference $=((19-18) \times 100 \%)): 10$

$=(1 \times 100 \%): 10=10 \%$

Based on the calculations above, it can be seen that there is a difference in the level of divergence in the official workshop and the ordinary workshop. Ordinary workshops have a higher divergence rate than official workshops. The difference in the level of divergence is $10 \%$. Therefore, the opinion regarding the formulation of the first problem of this study which states that there is a difference in the level of divergence in official workshops and ordinary workshops is acceptable.

\section{Second Hypothesis Test}

To test the second hypothesis which states that there are differences in the effectiveness of ${ }_{3} \mathrm{P}$ (People, Process, Physical evidence) between official workshops and ordinary workshops, we use calculations based on the Mann-Whitney U Test analysis.

People Variable The first step to determine whether or not there is a difference in the effectiveness of People between official workshops and regular workshops is to look at the results of Zhitung. It is said to be significant or there is a difference if Zcount $>$ Ztable, or it could be if the probability is 0.05 . With the help of the SPSS program, the following results were obtained:

Table 3. Differences in People's Effectiveness at Authorized and Ordinary Motorcycle Workshops.

\begin{tabular}{cccccc}
\hline Variable $3 \mathrm{P}$ & Z count & $\begin{array}{c}-\mathrm{Z} \text { table } \\
(-1,928)\end{array}$ & $\begin{array}{c}\text { asymp. Sig } \\
\text { (probability) }\end{array}$ & 0.05 & Information \\
\hline People & -0.225 & $-1,928$ & 0.822 & 0.05 & Significant/Same \\
\hline
\end{tabular}

From the table above, Zcount is -0.225. Based on the provisions of the Mann-Whitney Test analysis test, by comparing $\mathrm{Z}$ count with $\mathrm{Z}$ table at a significance level $(\alpha)=0.05$, namely:

-Ztable -0.225 Ztable, (p) o.822

From the results of the analysis on the Mann-Whitney Test, it can be seen that there is no difference in the effectiveness of people in official workshops with ordinary workshops. So it can be concluded that there is no difference in the effectiveness of people in official workshops with ordinary workshops.

Process Variables The first step to determine whether or not there is a difference in Process effectiveness between official workshops and regular workshops is to look at the results of Zcount. It is said to be significant or there is a difference if Zcount > Ztable, or it could be if the probability is 0.05 . With the help of the SPSS program, the following results were obtained: 
Table 4. Differences in Process Effectiveness at Official and Ordinary Motorcycle Workshops.

\begin{tabular}{cccccc}
\hline Variable $3 \mathrm{P}$ & Z count & $\begin{array}{c}-\mathrm{Z} \text { table } \\
(-1,928)\end{array}$ & $\begin{array}{c}\text { asymp. Sig } \\
\text { (probability) }\end{array}$ & 0.05 & Information \\
\hline People & -0.122 & $-1,928$ & 0.903 & 0.05 & Not Significant/Same \\
\hline
\end{tabular}

From the table above, Zcount is -0.122. Based on the provisions of the Mann-Whitney Test analysis test, by comparing $\mathrm{Z}$ count with $\mathrm{Z}$ table at a significance level $(\alpha)=0.05$, namely:

$$
\text { -Ztable -0.122 Ztable, (p) o.903 }
$$

From the results of the analysis on the Mann-Whitney Test, it can be seen that there is no difference in the effectiveness of the process in official workshops with ordinary workshops. So it can be concluded that there is no difference in the effectiveness of the process in official workshops with ordinary workshops.

Variable Physical evidence The first step to determine whether or not there is a difference in the effectiveness of Physical evidence between official workshops and regular workshops is to look at the results of Zcount. It is said to be significant or there is a difference if Zcount $>$ Ztable, or it could be if the probability is 0.05 . With the help of the SPSS program, the following results were obtained:

Table 5. Differences in the Effectiveness of Physical Evidence in Authorized and Ordinary Motorcycle Workshops.

\begin{tabular}{cccccc}
\hline Variable $3 \mathrm{P}$ & $\mathrm{Z}$ count & $\begin{array}{c}-\mathrm{Z} \text { table } \\
(-1,928)\end{array}$ & $\begin{array}{c}\text { asymp. Sig } \\
\text { (probability) }\end{array}$ & 0.05 & Information \\
\hline Process & -0.116 & $-1,928$ & 0.908 & 0.05 & Not Significant/Same \\
\hline
\end{tabular}

From the table above, Zcount is -o.116. Based on the provisions of the Mann-Whitney Test analysis test, by comparing $\mathrm{Z}$ count with $\mathrm{Z}$ table at a significance level $(\alpha)=0.05$, namely:

$$
\text { -Ztable -0.116 Ztable, (p) o.9o8 }
$$

From the results of the analysis on the Mann-Whitney Test, it can be seen that there is no difference in the effectiveness of physical evidence in official workshops with ordinary workshops. So it can be concluded that there is no difference in the effectiveness of physical evidence in official workshops with ordinary workshops. From the results of the analysis above and with the following effectiveness criteria: (1). Not effective, if 5 mean 10 (2). Less effective, if 10 mean 15 (3). Quite effective, if 15 mean 20 (4). Effective, if 20 mean 25 (5). Very effective, if the mean $=25$ then the effectiveness of the ${ }_{3}$ Ps in official workshops and regular workshops can be formulated in the form of a table as follows:

Table 6. The Effectiveness of 3 Ps (People, Process, Physical Evidence) at Official and Ordinary Workshops

\begin{tabular}{lrll}
\multirow{2}{*}{ Variable ${ }_{3} \mathrm{P}$} & mean & Effective Status & Information \\
\cline { 3 - 4 } & & Effective/Not Effective & Different/Same \\
\hline People & 20.74 & Effective & You're welcome \\
Process & 20.2 & Effective & You're welcome \\
Physical evidence & 20.14 & Effective & You're welcome \\
\hline
\end{tabular}

Based on the results of the analysis obtained from the comparison of the level of effectiveness in the three marketing mix variables above, the hypothesis proposed by the researcher, that there are differences in the effectiveness of the ${ }_{3} \mathrm{Ps}$ in the workshop at different levels of complexity and divergence, between official motorcycle repair shops and ordinary motorcycle repair shops is not proven. 
Third Hypothesis Test To test the third hypothesis which states that there is a difference in performance between official workshops and ordinary workshops at different levels of complexity and divergence, using calculations using the Mann - Whitney U Test analysis. Before conducting the analysis, the researcher converted the types of existing services. This step is done because the weight of each type of service is different. The type of medium service and heavy service will be converted to light serve. In an ordinary workshop, one medium service has a value of 2 times a light service and one heavy service has a value of 5 times a light service. Meanwhile, in official workshops, one medium service has a value of 1.5 times a light service and one heavy service has a value of 5 times a light service. Workshop performance data can be seen in appendix 9-10 and data after conversion can be seen in appendix 11-12. The data analyzed is the workshop performance data after being converted. The step to find out whether or not there is a difference in performance between an official workshop and a regular workshop is to look at the results of the $\mathrm{Z}$ count for each type of service. It is said to be significant if $\mathrm{Z}$ count $>\mathrm{Z}$ table. Can also compare the probability of each type of service. There is a difference if the probability is 0.05 . By using the calculation of the SPSS program on the computer, the following results are obtained. The step to find out whether or not there is a difference in performance between an official workshop and a regular workshop is to look at the results of the $Z$ count for each type of service. It is said to be significant if $\mathrm{Z}$ count $>\mathrm{Z}$ table. Can also compare the probability of each type of service. There is a difference if the probability is 0.05 . By using the calculation of the SPSS program on the computer, the following results are obtained. The step to find out whether or not there is a difference in performance between an official workshop and a regular workshop is to look at the results of the $\mathrm{Z}$ count for each type of service. It is said to be significant if $Z$ count $>Z$ table. Can also compare the probability of each type of service. There is a difference if the probability is 0.05 . By using the calculation of the SPSS program on the computer, the following results are obtained.

Table 7. Statistical Test of the Difference between Official Workshop Performance and Ordinary Workshop

\begin{tabular}{cccccc}
\hline Service Type & Z count & $\begin{array}{c}-Z \text { Z table } \\
(-1,928)\end{array}$ & $\begin{array}{c}\text { asymp. Sig } \\
\text { (probability) }\end{array}$ & 0.05 & Information \\
\hline Light Service & $-6,710$ & $-1,928$ & 0.000 & 0.05 & Significant/Different \\
Medium Service & -6.786 & $-1,928$ & 0.000 & 0.05 & Significant/Different \\
Heavy Service & -6.603 & $-1,928$ & 0.000 & 0.05 & Significant/Different \\
Total Service & -6.675 & $-1,928$ & 0.000 & 0.05 & Significant/Different \\
\hline
\end{tabular}

\subsection{Discussion}

After analyzing the data, the results obtained will be discussed. From the data analysis process above, the results can be formulated in the form of a schema to facilitate the discussion, as follows: 


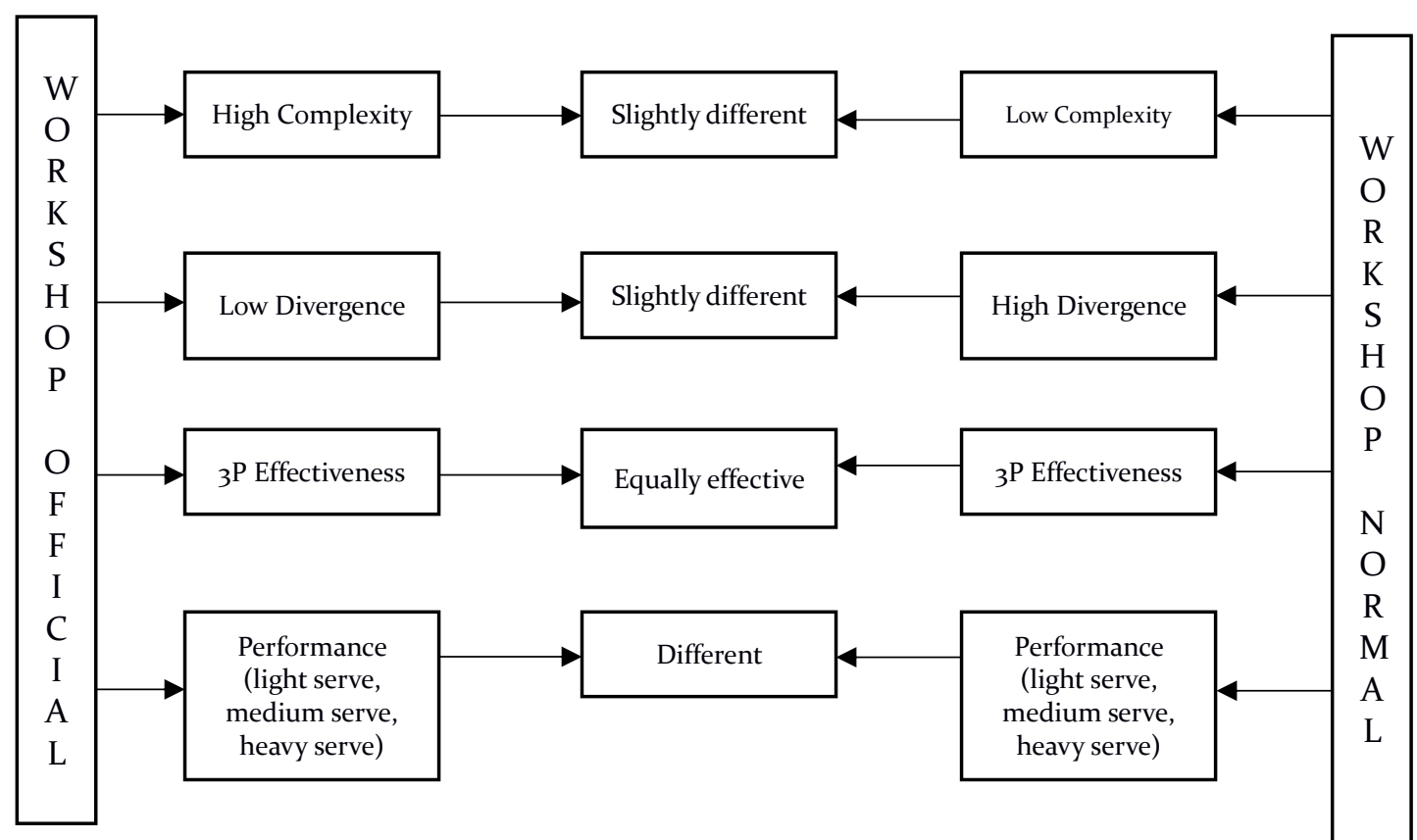

Figure 1. Comparison Scheme of Complexity and Divergence, Effectiveness of 3 Ps and Performance in Authorized Workshops with Ordinary Workshops.

Different levels of complexity and divergence. The level of complexity in official workshops is different from the level of complexity in ordinary workshops. Official workshops have a relatively higher level of complexity than ordinary workshops. Differences are seen in:

Queuing procedure. Official workshops provide a special queue number in serving customers who will perform the service after the customer registers. Whereas in ordinary workshops in responding to customer queues, workshop employees only remember which customer arrived at the workshop first.

Specific standards applied in handling consumer demand. At authorized workshops, customers are only allowed to submit all complaints regarding service quality, warranty requests and all requests through special employees (customer service). Meanwhile, at regular workshops, customers can submit all complaints regarding service quality, warranty requests and all requests through the workshop owner or directly to technician employees.

Mandatory standard that must be done by mechanics in handling motorcycle services. In official repair shops, technicians are required to carry out a series of mandatory procedures in handling motorcycle services, although according to technicians, these procedures can be eliminated because they are deemed unnecessary because the condition of the motorbike is good. Meanwhile, in ordinary workshops, there is no mandatory standard that mechanics must do in handling services.

The level of divergence in official workshops is different from the level of divergence in ordinary workshops. This difference is very important because it involves mandatory procedures in carrying out the service process and will affect the quality of motorcycle service services which can be seen in the performance of the motorcycle after being serviced. In ordinary workshops, the level of divergence is relatively higher than the level of divergence in official workshops. This difference can be seen in the freedom of mechanics in handling motorcycle services. In ordinary workshops, technicians are allowed to omit one or several mandatory steps in completing a service if the condition or performance of the motor is considered good. This can be a problem for both the customer and the repair shop. Technicians may make mistakes in assessing motor performance before servicing. Meanwhile, in official workshops, technicians are required to carry out a series of mandatory procedures in handling motorbike services, although according to technicians, these procedures can be eliminated because they are deemed unnecessary because the condition of the motorbike is good. This is considered to take a relatively long 
time, but what is being done is a form of service that is oriented towards customer satisfaction and service quality. The workshop pays attention to the performance of the motorbike in detail before the motorbike is serviced.

The effectiveness of ${ }_{3}$ Ps between official workshops and ordinary workshops. In the field of marketing mix services, there are 7 concepts, namely; product, price, promotion, place, people, process and physical evidence. In this study, the 7 concepts are divided into 2 parts and only examines one part, namely the 3 P group (people, process and physical evidence). Effectiveness of people, which means the ability of the aspects of people implemented by the company as the right tool to meet needs or satisfy customers according to consumer perceptions. Aspects in it include the attitude of employees in carrying out their duties to serve customers and customer knowledge. Process effectiveness, which means the ability of the process aspects carried out by the company as the right tool to meet the needs or satisfy customers according to consumer perceptions. The aspects in it include the steps to fulfill the service and the flow of activities in getting the service. The effectiveness of physical evidence which means the ability of the physical evidence aspects carried out by the company as the right tool to meet the needs or satisfy customers according to consumer perceptions. Aspects in it include equipment, facilities, facility layout, and room design. From the results of the analysis, it was found that the effectiveness of $3 \mathrm{P}$ between official workshops and ordinary workshops at different levels of complexity and divergence was equally effective. The community considers the ability of ordinary workshops to be quite the same as official workshops. Ordinary workshops and authorized workshops both have Steps and activities to fulfill and obtain services, as well as effective equipment and facilities according to customer perceptions. All information received by the public regarding the mandatory procedures applied to official workshops and the flexibility given to ordinary workshops does not affect their decision to use their services. Information about the difference in character between official workshops and ordinary workshops does not make the public have a different perception between the two types of workshops. Because in one part of the ${ }_{3} \mathrm{P}$ group there are no differences, it can be ascertained that in other groups, namely product, price, promotion, place, there are differences between official workshops and ordinary workshops. Information about the difference in character between official workshops and ordinary workshops does not make the public have a different perception between the two types of workshops. Because in one part of the ${ }_{3} \mathrm{P}$ group there is no difference, it can be ascertained that in other groups, namely product, price, promotion, place, there are differences between official workshops and ordinary workshops. Information about the difference in character between official workshops and ordinary workshops does not make the public have a different perception between the two types of workshops. Because in one part of the ${ }_{3} \mathrm{P}$ group there are no differences, it can be ascertained that in other groups, namely product, price, promotion, place, there are differences between official workshops and ordinary workshops.

Performance of official workshops with ordinary workshops. At different levels of complexity and divergence in the case studies on official workshops and ordinary workshops, differences in performance were found. The performance in question is the level of service implementation. The implementation of the service in question is the level of light service, medium service and heavy service. Official workshops with a high level of complexity and low level of divergence have a higher level of performance than the performance of ordinary workshops that have a low level of complexity and a high level of divergence. The relatively high level of complexity does not affect customers not to use service services at authorized workshops. In authorized workshops, a higher level of performance can occur because authorized workshops have free service services which are a form of workshop cooperation with authorized Yamaha dealers. People take advantage of their rights which of course can only be fulfilled by official workshops. From the three discussions above, it can be stated that at a high level of complexity it is not certain that the level of divergence is also high. Vice versa, at a high level of divergence is not necessarily a high level of complexity. The different levels of complexity and divergence also do not cause the effectiveness of the ${ }_{3} \mathrm{Ps}$ (people, process and physical evidence) to be different for different service providers. Service providers that have the same effectiveness can actually have different performances. So the effectiveness of ${ }_{3} \mathrm{P}$ does not always affect the performance of service providers. The performance

Int J on Social Science, Econ \& Art, Vol. 11, No. 2 Aug 2021: 60-72 
of service providers can be influenced by other elements of the marketing mix, namely; product, price, promotion, place.

\section{Conclusion}

After conducting the analysis and discussion, the researcher can conclude several things, including: (1). There is a difference in the level of complexity and level of divergence in the official workshop (Yamaha Arditya Buana Motor motorcycle workshop) and the regular workshop (Imung Baru Motor motorcycle workshop). The official workshop has a high level of complexity and a low level of divergence. While ordinary workshops have a low level of complexity and a high level of divergence. (2). There is no difference in the effectiveness of the ${ }_{3} \mathrm{Ps}$ (people, process, physical evidence) between official workshops (Yamaha Arditya Buana Motor motorcycle workshop) and regular workshops (Imung Baru Motor motorcycle workshop) with different levels of complexity and divergence. Official workshops and regular workshops are equally effective in terms of 3 P. (3). There is a difference in performance between the official workshop (Yamaha Arditya Buana Motor motorcycle workshop) and the regular workshop (Imung Baru Motor motorcycle workshop) with different levels of complexity and divergence. The difference in all types of service, both light service, medium service and heavy service.

\section{REFERENCES}

Ahmad, A. M. K. (2007). The impact of competitive environment on the service marketing mix strategy of health organisations in developing countries: Jordanian private sector hospital senior managers perspective. University of Huddersfield.

Ahrens, T., \& Chapman, C. S. (2006). Doing qualitative field research in management accounting: Positioning data to contribute to theory. Handbooks of Management Accounting Research, 1, 299-318.

Akraush, M. N. (2005). The Services Marketing Mix Paradigm: Is It Still Appropriate for Today's Service Businesses? Al-Balqa Journal for Research and Studies 8 (2) 11 8 (2), للبقاء للبحوث والدراسات.

Armbrust, M., Fox, A., Griffith, R., Joseph, A. D., Katz, R. H., Konwinski, A., Lee, G., Patterson, D. A., Rabkin, A., \& Stoica, I. (2009). Above the clouds: A berkeley view of cloud computing. Technical Report UCB/EECS-200928, EECS Department, University of California ....

Ba, S., \& Johansson, W. C. (2008). An exploratory study of the impact of e-service process on online customer satisfaction. Production and Operations Management, 17(1), 107-119.

Belzowski, B. M., Henderson, A., \& Koppinger, P. (2007). Inside India: Indians view their automotive future. Somers, NY: IBM Global Services, c2007.

Bitner, M. J., Ostrom, A. L., \& Morgan, F. N. (2008). Service blueprinting: a practical technique for service innovation. California Management Review, 50(3), 66-94.

Bowen, D. E., \& Lawler III, E. E. (2006). The empowerment of service workers: What, why, how, and when. Managing Innovation and Change, 33, 155-169.

Cusumano, M., Kahl, S., \& Suarez, F. (2008). A THEORY OF SERVICES IN PRODUCTS INDUSTRIES Paper 242. Retrieved March, 20, 2015.

Dominici, G. (2009). From marketing mix to e-marketing mix: a literature overview and classification. International Journal of Business and Management, 4(9), 17-24.

Erickson, K. A. (2009). The hungry cowboy: Service and community in a neighborhood restaurant. Univ. Press of Mississippi.

Goi, C. L. (2009). A review of marketing mix: 4 Ps or more. International Journal of Marketing Studies, 1(1), 2-15.

Halinen, A., \& Törnroos, J.-Å. (2005). Using case methods in the study of contemporary business networks. Journal of Business Research, 58(9), 1285-1297.

Ho, H., \& Hung, C. (2008). Marketing mix formulation for higher education: An integrated analysis employing analytic hierarchy process, cluster analysis and correspondence analysis. International Journal of Educational Management.

Hume, M., Mort, G. S., Liesch, P. W., \& Winzar, H. (2006). Understanding service experience in non-profit performing arts: Implications for operations and service management. Journal of Operations Management, $24(4), 304-324$.

Ismail, I., Haron, H., Ibrahim, D. N., \& Isa, S. M. (2006). Service quality, client satisfaction and loyalty towards audit firms: Perceptions of Malaysian public listed companies. Managerial Auditing Journal.

Janssen, H. (2005). Study on the post-tsunami rehabilitation of fishing communities and fisheries-based livelihoods in Indonesia. International Collective in Support of Fishworkers, Banda Aceh/Jakarta, December. 
Kadam, P., \& Bhalerao, S. (2010). Sample size calculation. International Journal of Ayurveda Research, 1(1), 55.

Kashdan, T. B., \& Rottenberg, J. (2010). Psychological flexibility as a fundamental aspect of health. Clinical Psychology Review, 3o(7), 865-878.

Keh, H. T., \& Pang, J. (2010). Customer reactions to service separation. Journal of Marketing, 74(2), 55-70.

Kimmel, A. J. (2010). Connecting with consumers: Marketing for new marketplace realities. Oxford University Press.

Kirkpatrick, I., Ackroyd, S., \& Walker, R. (2005). The new managerialism and public service professions. Hampshire: Palgrave Macmillan.

Laroche, M., Nepomuceno, M. V., \& Richard, M. (2010). How do involvement and product knowledge affect the relationship between intangibility and perceived risk for brands and product categories? Journal of Consumer Marketing.

Laroche, M., Yang, Z., McDougall, G. H. G., \& Bergeron, J. (2005). Internet versus bricks-and-mortar retailers: An investigation into intangibility and its consequences. Journal of Retailing, 81(4), 251-267.

Lindberg, N., \& Nordin, F. (2008). From products to services and back again: Towards a new service procurement logic. Industrial Marketing Management, 37(3), 292-300.

Long, W. (2010). Study on the Influence of Commitment on Customer Behavior in the Stage of Pre-purchase and Post-Purchase. 2010 International Conference on Management of E-Commerce and e-Government, 188-191.

Longo, M., Mura, M., \& Bonoli, A. (2005). Corporate social responsibility and corporate performance: the case of Italian SMEs. Corporate Governance: The International Journal of Business in Society.

Malai, V., \& Speece, M. (2005). Cultural impact on the relationship among perceived service quality, brand name value, and customer loyalty. Journal of International Consumer Marketing, 17(4), 7-39.

Moody, L. E., Slocumb, E., Berg, B., \& Jackson, D. (2004). Electronic health records documentation in nursing: nurses' perceptions, attitudes, and preferences. CIN: Computers, Informatics, Nursing, 22(6), 337-344.

Mudie, P., \& Cottam, A. (2010). Management and marketing of services. Routledge.

Nachar, N. (2008). The Mann-Whitney U: A test for assessing whether two independent samples come from the same distribution. Tutorials in Quantitative Methods for Psychology, 4(1), 13-20.

Oke, A., Munshi, N., \& Walumbwa, F. O. (2009). The influence of leadership on innovation processes and activities. Organizational Dynamics, 38(1), 64-72.

Papazoglou, M. P., \& Van Den Heuvel, W.-J. (2006). Service-oriented design and development methodology. International Journal of Web Engineering and Technology, 2(4), 412-442.

Prahinski, C., \& Kocabasoglu, C. (2006). Empirical research opportunities in reverse supply chains. Omega, 34(6), 519-532.

Runeson, P., \& Höst, M. (2009). Guidelines for conducting and reporting case study research in software engineering. Empirical Software Engineering, 14(2), 131-164.

Seidel, S., Müller-Wienbergen, F., \& Rosemann, M. (2010). Pockets of creativity in business processes. Communications of the Association for Information Systems, 27(1), 415-436.

Shanmoogam, R. (2006). An exploratory study on customer service in Fedics Food Service KZN.

Siddiqui, M. H., \& Sharma, T. G. (2010). Analyzing customer satisfaction with service quality in life insurance services. Journal of Targeting, Measurement and Analysis for Marketing, 18(3), 221-238.

Simon, F., \& Usunier, J.-C. (2007). Cognitive, demographic, and situational determinants of service customer preference for personnel-in-contact over self-service technology. International Journal of Research in Marketing, 24(2), 163-173.

Skibniewski, M. J., \& Ghosh, S. (2009). Determination of key performance indicators with enterprise resource planning systems in engineering construction firms. Journal of Construction Engineering and Management, 135(10), 965-978.

Stiglingh, M. (2009). Developing a model to evaluate the quality of the services rendered by the South African Revenue Service. University of Pretoria.

Teece, D. J. (2010). Business models, business strategy and innovation. Long Range Planning, 43(2-3), 172-194.

Weber, L. (2009). Marketing to the social web: How digital customer communities build your business. John Wiley \& Sons.

Zineldin, M., \& Philipson, S. (2007). Kotler and Borden are not dead: myth of relationship marketing and truth of the 4 Ps. Journal of Consumer Marketing. 